\title{
News media coverage of climate change in India 1997-2016: using automated content analysis to assess themes and topics
}

Keller, Tobias R ; Hase, Valerie ; Thaker, Jagadish ; Mahl, Daniela ; Schäfer, Mike S

\begin{abstract}
News media play an important role for public awareness and perception of climate change - and thus citizens' behavior. Few studies focus on media coverage in poor and developing countries such as India - the third-largest polluter and an important player in global climate change policies. Further, even these few studies on Indian media coverage span short time periods, focus on specific events, and evaluate pre-defined themes. Applying LDA topic modeling on 18,224 climate change articles published between 1997 and 2016 in two Indian newspapers, we find that climate change coverage in India has increased substantially in the last 20 years. We categorized the coverage into 28 different topics related to four overarching themes: "Climate Change Impacts", "Climate Science", "Climate Politics", and "Climate Change and Society". Climate change has gained more media attention since 2007 in general with a particular increase in focus on the theme "Climate Change Impacts". Implications about shifting media discourses and its potential to educate people and change policies are discussed.
\end{abstract}

DOI: https://doi.org/10.1080/17524032.2019.1643383

Posted at the Zurich Open Repository and Archive, University of Zurich

ZORA URL: https://doi.org/10.5167/uzh-176063

Journal Article

Accepted Version

Originally published at:

Keller, Tobias R; Hase, Valerie; Thaker, Jagadish; Mahl, Daniela; Schäfer, Mike S (2020). News media coverage of climate change in India 1997-2016: using automated content analysis to assess themes and topics. Environmental Communication, 14(2):219-235.

DOI: https://doi.org/10.1080/17524032.2019.1643383 


\section{News Media Coverage of Climate Change in India 1997-2016:}

\section{Using Automated Content Analysis to Assess Themes and Topics}

\section{Authors:}

(Corresponding author) Tobias R. Keller, IKMZ - Department of Communication and Media Research, University of Zurich, Andreasstrasse 15, CH-8050, Switzerland, t.keller@ikmz.uzh.ch, Tel. +41 4463520 37, Twitter: @Tobias_Keller, orcid.org/0000-0001$5263-4812$

Valerie Hase, IKMZ - Department of Communication and Media Research, University of Zurich, Andreasstrasse 15, CH-8050, Switzerland, v.hase@ikmz.uzh.ch, orcid.org/0000-0001$6656-4894$

Jagadish Thaker, School of Communication, Journalism \& Marketing (Te Pou Aro Korero), Massey University, Wellington 6140, New Zealand, j.thaker@massey.ac.nz, orcid.org/00000003-4589-7512

Daniela Mahl, Institute for Journalism and Communication Studies, University of Hamburg, Allende-Platz 1, 20146 Hamburg, Germany, daniela.mahl@uni-hamburg.de, orcid.org/0000-0002$5330-6885$

Mike S. Schäfer, IKMZ - Department of Communication and Media Research, University of Zurich, Andreasstrasse 15, CH-8050, Switzerland, m.schaefer@ikmz.uzh.ch, orcid.org/00000002-0847-7503 


\begin{abstract}
News media play an important role for public awareness and perception of climate change and thus citizens' behavior. Few studies focus on media coverage in poor and developing countries such as India - the third largest polluter and an important player in global climate change policies. Further, even these few studies on Indian media coverage span short time periods, focus on specific events, and evaluate pre-defined themes. Applying LDA topic modeling on 18,224 climate change articles published between 1997 and 2016 in two Indian newspapers, we find that climate change coverage in India has increased substantially in the last twenty years. We categorized the coverage into 28 different topics related to four overarching themes: "Climate Change Impacts", "Climate Science”, "Climate Politics”, and "Climate Change and Society". Climate change has gained more media attention since 2007 in general with a particular increase in focus on the theme "Climate Change Impacts". Implications about shifting media discourses and its potential to educate people and change policies are discussed.
\end{abstract}

\title{
Keywords
}

Climate change; media coverage; India; topic modeling; longitudinal analysis

\section{Acknowledgements}

We thank the two reviewers for their time and effort to improve our manuscript. Additionally we are grateful to Lea Hellmüller, Uma Shankar Pandey, and Martin Wettstein for their feedback on previous versions of this manuscript. We also thank Anna Staender, Katherine M. Engelke, Korinna Olivia Lindemann and Rafael Schwab for their external coding of topics. 


\section{Introduction}

Climate change is one of the greatest problems facing humankind in the $21^{\text {st }}$ century. Scientists agree that unless greenhouse gas emissions sharply decline in the near future, the negative environmental and socio-political impacts of climate change will intensify (Figueres et al., 2017; IPCC, 2013), particularly in poor and developing countries such as India (DARA, 2012; NAPCC, 2008). As a third largest emitter of carbon dioxide - set to double its emissions by 2030 compared to 2012 (Dubash, Khosla, Rao, \& Bhardwaj, 2018) - yet a country ranked high in vulnerability due to a large proportion of poor and energy starved Indians (DARA, 2012), India's climate policy debates are likely to impact global mitigation goals.

News media play an important role for public awareness and perception of climate change (Moser, 2010). Media coverage of climate change has been shown to set the policy agenda on climate change (Carmichael \& Brulle, 2016; Liu, Lindquist, \& Vedlitz, 2011; Weingart, Engels, \& Pansegrau, 2016), to influence public discourses about climate change (Carvalho, 2010; Nisbet, 2009), and to impact people's perceptions and behavioral intentions regarding climate change (e.g. Arlt, Hoppe, \& Wolling, 2011).

As a result, analyses of media coverage of climate change have emerged as a key area of study in environmental communication. Scholarly analyses on media reporting have grown considerably since the 2000s, and have diversified concerning their topics and methods (Schäfer \& Schlichting, 2014). However, most studies still analyze news media coverage of climate change in developed countries, e.g., in the US, the UK, Australia, or European countries (see Carvalho, 2007; Painter, 2014; Schäfer \& Schlichting, 2014). These studies show that national characteristics, such as domestic ideological cultures (Brossard, Shanahan, \& McComas, 2004; Lück, Wessler, Wozniak, \& Lycarião, 2016; Painter \& Ashe, 2012; Schmidt, Ivanova, \& Schäfer, 2013), journalistic norms (M. T. Boykoff \& Boykoff, 2004), domestic media systems (Schäfer, 2015) and extreme weather events (Schmidt et al., 2013), 
among others, play an important role in shaping media coverage about climate change. But these studies have largely ignored other, equally important countries - namely developing countries and "emerging economies" such as India. Understanding Indian media coverage will help understand evolving domestic agendas about climate change, with implications for attaining national and global mitigation targets. In addition, India plays a key role in international negotiations due to its growing economy and emissions, through its participation in negotiation groups such as BASIC (Brazil, South Africa, India, and China) and G77 (Dubash, 2012), and through its attempts to gain issue leadership in international climate politics (Jogesh, 2012; Wessler, Wozniak, Hofer, \& Lück, 2016).

This study aims to fill this gap by analyzing media coverage of climate change in India, and by going beyond the few previous studies which have assessed Indian media coverage of climate change (Billett, 2010; Jogesh, 2012; Mittal, 2012; Schmidt \& Schäfer, 2015). Most of these studies have focused on small media samples over short time spans or on specific events, such as the release of the IPCC reports in 2007 (Mittal, 2012), the climate change conference in Copenhagen in 2009 (Painter \& Ashe, 2012), or similar conferences (Lück et al., 2016). Furthermore, some of them simply quantified the amount of media attention for the issue without identifying overarching themes in the coverage (Schmidt et al., 2013), focused on a narrow topic such as climate justice (Schmidt \& Schäfer, 2015) ${ }^{1}$ or studied a predefined set of issues such as risk, responsibility, or scientific consensus (Billett, 2010; Jogesh, 2012; Mittal, 2012). In addition, these studies mostly covered short periods of time, from three (Lück et al., 2016; Mittal, 2012; Painter \& Ashe, 2012) to six months (Jogesh, 2012), with few spanning five years or more (Billett, 2010; Schmidt et al., 2013). Furthermore, previous studies did not analyze the development of Indian climate change coverage for recent years, for example after the change of government in May 2014,

\footnotetext{
${ }^{1}$ In the following, we differentiate between themes and topics: overarching themes, e.g., "Climate Politics", consist of several, more specific topics, e.g., International summits and Regional summits.
} 
when political changes may have led to corresponding discursive changes. For example, a single political party received a majority in Parliament, leading to a degree of political stability not seen since 1984 (Sardesai, 2014). The new government was led by charismatic leader Narendra Modi, who has cultivated an image of a global leader, particularly championing solar energy and had written a book on climate change, titled, "Convenient Action: Gujarat's Response to Challenges of Climate Change.” The Environmental Ministry was also renamed as Ministry for Environment, Forests, and Climate Change, indicating the new government's focus on climate change in domestic policy making (Bureau, 2014). Internationally, India has signed the Paris Agreement, with a pledge for voluntary emissions and is expected to show leadership on climate change (Jaiswal, 2017).

We address these gaps in scholarship by conducting the largest analysis of Indian media coverage of climate change to date, analyzing coverage from 1997, the year the Kyoto protocol was implemented, until 2016, a year after the Paris climate agreement. Using an automated content analysis on 18,224 news articles from the two largest-circulated Englishlanguage newspapers, the Times of India and The Hindu, our inductive approach answers three research questions:

RQ1: How salient was climate change in Indian media from 1997 to 2016?

RQ2: Which themes and topics can be identified in Indian media coverage about climate change?

RQ3: How prevalent were these themes and topics between 1997 and 2016?

\section{India and climate change}

India is one of the largest countries in the world both geographically and in terms of population. Even though per-capita income is moderate and the country ranks only 130th 
globally in Human Development as measured by the UN (HDR, 2016), India has the sixthlargest Gross Domestic Product in the world and has become the world's third largest greenhouse gas (GHG) emitter (Dubash, 2012; IEA, 2013).

India is doubly burdened by climate change. On the one hand, India is already acutely affected by climate change induced extreme weather events, projected to increase in intensity and magnitude within the next decades (DARA, 2012). On the other hand, climate change could constrain India's economic growth by negatively impacting energy access and energy security (Schmidt \& Schäfer, 2015) and, connected to it, threatens to slow down or reverse India's national development goals such as reducing poverty and improving public health (Hijioka et al., 2014; NAPCC, 2008).

Therefore, climate change has emerged as a key issue for Indian policymakers since the 1990s. India's position was initially reactive, trying to externalize the problem and protect its right for economic development without committing to emission reductions (Jasanoff, 1993; Rajan, 1997). This slightly changed in the 2000s when India acceded to the Kyoto Protocol. With the establishment of the Prime Minster Council of Climate Change in 2007, a major policy shift took place: addressing climate change was reframed in a "co-benefits" paradigm to achieve domestic priorities of poverty alleviation and address climate change through eight national missions, ranging from sustainable agriculture, energy efficiency, sustainable habitat, sustaining the Himalayan ecosystem, solar, water, and strategic knowledge missions (NAPCC, 2008). Just days prior to the important Conference of Parties (COP) 15 meeting in Copenhagen in 2009, attended by heads of state from various countries, India voluntarily offered to reduce its emission intensity of GDP by 20-25\% by 2020 compared to 2005 levels, following the targets announced by China. More recently, India ratified the Paris Agreement by pledging to lower its emissions intensity of GDP by $33-35 \%$ by 2030 below 2005 levels, to increase the share of renewable energy to $40 \%$ by 2030 , and to 
increase additional carbon sink of $2.5-3 \mathrm{GtCO}_{2}$ through additional forest and tree cover by 2030 (Jaiswal, 2017).

In contrast to these political measures, however, a large majority of the Indian public has been shown to still know very little about climate change (Lee, Markowitz, Howe, Ko, \& Leiserowitz, 2015; Leiseriowitz \& Thaker, 2012), further exacerbating the country's vulnerability to climate change. Most Indians are not familiar with the term climate change and may lack a conceptual framework to make sense of changing weather patterns. This may hinder their ability to take appropriate action themselves, but also their support for policies to mitigate and adapt to climate change impacts. As media play an important role in educating the public about climate change, analyses of media coverage will help reveal what people read and possibly learn about climate change.

\section{Literature Review: Indian Media Coverage of Climate Change}

So far, only few studies have analyzed Indian media coverage about climate change (for an overview see (Thaker, 2017), and these studies have a number of shortcomings: they are often restricted to relatively short periods of time and certain events (Jogesh, 2012; Mittal, 2012), do not analyze topics of media coverage at all (Schäfer, Ivanova, \& Schmidt, 2013; Schmidt et al., 2013), or focus on a small number of specific topics (Billett, 2010; Jogesh, 2012;

Mittal, 2012; Schmidt \& Schäfer, 2015). Some of their findings, however, are still of relevance to our research. In sum, they have shown that (1) the amount of media coverage related to climate change is relatively low compared to other countries, albeit it has increased in recent years, and that (2) while coverage accurately reports on the scientific consensus on anthropogenic climate change, the (3) coverage of global politics still trumps local priorities, with low coverage of domestic Indian policies.

Issue Salience: How Prominent Was Climate Change in Indian Media? 
Available analyses of climate change's salience in Indian media - i.e., of "issue attention" or "media attention" - found that Indian media coverage of global warming has been rather low in comparison to other countries (M. T. Boykoff et al., 2018; Schmidt et al., 2013). Schmidt et al. (2013), for example, found that climate change appeared in 0.28 percent of Indian newspaper articles between 1997 and 2009, compared to 0.55 percent in China, 0.67 percent in the US, 0.99 percent in the UK or 1.42 percent in Australia.

The temporal development of Indian media coverage, however, was largely similar to other countries. Overall, coverage was relatively low in the 1990s and early 2000s. Billett (2010), for example, found only 248 articles containing key terms related to climate change in four major Indian newspapers - The Times of India, The Hindu, Hindustan Times, and The Indian Express - from January 2002 to June 2007. Similarly, Mittal (2012) analyzed three newspapers - Hindustan Times, The Indian Express, and The Times of India - between February 2007 (release of the IPCC Fourth Assessment report) and October 2007 (Nobel Peace Prize awarded to the IPCC and Al Gore) and found only 191 articles covering climate change. In the late 2000s, however, coverage rose considerably. Media attention in India was highest during December 2009 and 2015, corresponding to the 15th Conference of Parties (COP15) in Copenhagen and the COP 21 in Paris (M. T. Boykoff et al., 2018). Between January 2002 and June 2007, online archival search of nine Indian newspapers between September 2009 and March 2010 resulted in 1,938 articles, illustrating a sharp rise in media attention to the issue during the COP 15 (Jogesh, 2012). However, the increase is still moderate in comparison to other countries: Schmidt et al. (2013) found that media attention has moderately increased by a factor of 2.9 in India between 1997 and 2009, compared with a factor of 10.5 in Australia and 16.4 in Indonesia.

Practically all of these studies, however, use data from the 1990s and 2000s, and do not cover the recent decade. As mentioned previously, the new government formed in 2014 
made a number of changes to prioritize climate change, including renaming the Environmental Ministry to include climate change and signing of the Paris agreement. To assess whether media attention for climate change has changed in the recent years, and how this compares to earlier trends, we ask: How salient was climate change in Indian media from 1997 to $2016 ?(R Q 1)$

\section{Prominent Themes and Topics in Indian Media Coverage of Climate Change}

We can identify overarching themes of coverage such as "Climate Politics" that themselves consist of different, more specific topics related to this theme such as Domestic issues. A large strand of previous research focuses on how Indian news media report on the theme of national and international "Climate Politics": They show that topics of global importance - such as the 'common but differentiated responsibility' for climate action between developing and developed countries (Post, Kleinen-von Königslöw, \& Schäfer, 2018) - have trumped local concerns and domestic politics in Indian media. For example, a study by (Jogesh, 2012) on media coverage during COP 15 found that a global angle dominated coverage, with $57 \%$ of articles focusing on international negotiations, with less attention paid to domestic politics and policies (21\%), the science of global warming (10\%) and business (5\%). Post et al. (2018) and Schäfer, Post, Schwab, and Kleinen-von Königslöw (2018) report similar results based on a quantitative content analysis and Billett (2010) supports these findings via qualitative analysis. However, Olausson (2014) also finds support for an increasing domestication of climate change coverage in India.

Another well investigated aspect of climate change coverage is how media report on the theme "Climate Science” (Ivanova, 2015) and especially the scientific consensus about climate change: The focus lay on the media's representation of scientific descriptions of the phenomenon of climate change as such - i.e., on changes in temperatures, precipitation patterns etc. - as well as on media descriptions of the environmental impacts of climate 
change, i.e., on water scarcity, biodiversity losses, desertification etc. Compared to countries such as the US and UK, Indian media have been shown to accurately report the scientific consensus on climate change (Brüggemann \& Engesser, 2017; Painter, 2011; Painter \& Ashe, 2012). Similarly, Billett (2010) found that all the 248 articles sampled reported global warming as real and $98 \%$ of articles reported that it is primarily caused due to human activities. Furthermore, Indian news articles were shown to be skeptical of climate contrarians, and to criticize the space skeptics are given in the Western press (Billett, 2010; Mittal, 2012). Furthermore, Indian media have been found to defend scientists and scientific institutions. Jogesh (2012) demonstrated that Indian newspapers defended the IPCC, even as the press highlighted misreporting Himalayan glacier retreat in the IPCC's Assessment Report, and particularly India's IPCC chief Rajendra Pachauri.

Two additional themes of Indian climate change reporting have been analyzed: “Celebrity Endorsements" and a "Spiritual Affinity with Nature”: First, some scholars argued that media coverage of climate change is celebrity driven (M. T. Boykoff \& Goodman, 2009) and pushed by cultural topics such as movie releases. Mittal (2012) argued that Al Gore, Hugo Chavez and Jacques Chirac are prominently featured in climate change reporting, thereby reducing the issue to isolated, celebrity-driven events. Second, Billett (2010) and Mittal (2012) describe Indian climate change reporting to be mentioning Indians' (alleged) spiritual affinity with nature. Mittal (2012) argued that such religious affiliation with the environment draws on both Indian religious traditions as well as environmental protection movements - exemplified by the tree huggers or the Indian Chipko movement. Interviews with Indian journalists underline this, showing that they see climate change impacting holy rivers in India as "bad news for Hindus” (Billett, 2010).

Practically all these studies focused on a set of predefined and specific themes or topics they analyzed in detail (e.g., risk, responsibility, or scientific consensus), often using qualitative methods (e.g. Billett, 2010; Schmidt \& Schäfer, 2015). But such a strategy does 
not provide a comprehensive overview of all possible themes and topics in Indian climate change coverage and how prevalent these are in comparison to one another. Therefore, we propose a large-scale, comprehensive, exploratory media analysis asking: Which themes and topics can be identified in Indian media coverage about climate change? (RQ2)

\section{Theme and Topic Development over Time}

While most previous studies focused on limited time periods, some of them hint towards an increased space for new and more diverse topics, focusing, for example, more on domestic vulnerability and responsibility (Mittal, 2012; Olausson, 2014). In light of former Environment Minister Jairam Ramesh seeking to transform India's image from a "deal-breaker" to a "dealmaker", Jogesh (2012) argues that public debate has opened to diverse voices, stands and ambitions. It is therefore possible that climate change reporting in India has not only changed quantitatively (regarding how much media attention is granted to climate change compared to other issues), but also in terms of the themes and topics that were covered over time. This would be in line with shifts in climate change coverage in other countries, for example in the US (Kirilenko \& Stepchenkova, 2012), Germany, or Canada (Ivanova, 2015). To assess this empirically, we analyze: How prevalent were themes and topics in Indian media coverage of climate change between 1997 and 2016? (RQ3)

\section{Data and Method}

To answer our research questions, we first assessed the proportion of articles dealing with climate change in relation to total coverage (Schäfer et al., 2013; Schmidt et al., 2013). Subsequently, we applied topic modeling with latent Dirichlet allocation (LDA; Blei, Ng, \& Jordan, 2003) to over 18,000 newspaper articles from two Indian newspapers covering climate change between 1997 and 2016. 


\section{Sample}

We chose the two largest circulated Indian English-language newspapers, Times of India and The Hindu, with about 2.8 million and 1.4 million circulation, respectively (Audit Bureau of Cirulations, 2018). Both newspapers play a vital role in national politics and English newspapers are considered to express the voices of the elite including influential policy makers in India, and as a result are important sources to identify shifting discourses of climate change policy (Jogesh, 2012).

Since both newspaper archives were available only from 1997 onwards, we retrieved all articles published between 1 January 1997 until 31 December 2016. Our search string consisted of three common terms for climate change which have been applied in many previous studies (Schmidt et al., 2013): “climate change*” OR "global warming*” OR "greenhouse effect*". The search string was used for a full-text search. After deleting duplicates, the final sample consisted of $\mathrm{N}=18,224$ articles $-10,785$ articles from The Hindu and 7,439 from Times of India. In addition, the total number of articles appearing every month in each newspaper was counted. The number of articles referring to climate change was then related to this total number of articles to calculate climate change coverage as a proportion of the absolute number of articles by month in percent (similar to Schmidt et al., 2013).

\section{LDA Topic Modeling}

To explore themes and topics in Indian climate change coverage, we applied unsupervised machine learning in the form of topic modeling with latent Dirichlet allocation (LDA) (Blei et al., 2003; Blei, 2012). Topic modeling is a form of automated content analysis that infers latent thematic structures called topics within documents in a "bottom-up" approach. These topics are clusters of words that co-occur across documents according to certain patterns (Jacobi et al., 2015) inferred by ignoring the order of words according to a "bags of words" assumption. The approach has the advantage of inferring topics from texts without any prior 
knowledge or extensive manual annotation. By using it, we can not only include large corpora over time, but also explore new topics that could not have been deducted theoretically. Compared to other explorative methods such as clustering, LDA topic modeling is advantageous due to its mixed-membership approach: It assumes that a document contains several topics instead of just one (Grimmer \& Stewart, 2013). And while topic modeling shares many aspects of Latent Semantic Analysis, it outperforms the method in predicting word associations and memory tasks with its generative probabilistic model (Griffiths, Steyvers, \& Tenenbaum, 2007). LDA is the most commonly used algorithm for topic modeling (Grimmer \& Stewart, 2013) and also applied here.

\section{Step 1: Select number of topics $k$}

We processed our corpus using the package "tm” (Feinerer, Hornik, \& Meyer, 2008) and calculated topic models using the package "topicmodels" (Grün \& Hornik, 2011) in R (R Development Core Team, 2017). ${ }^{2}$ As LDA topic models run unsupervised, some parameters need to be defined beforehand: These include the number of topics $(k)$ the model should produce and the hyperparameter $\alpha$ that affects how many topics a document will contain. Similar to (Jacobi et al., 2015, p. 95), we are analyzing "an issue that involves various events and viewpoints, [hence] it makes sense to define several clearly distinguishable topics." Therefore, we set $\alpha$ lower than the default, in this case $5 / k$. To find a suitable number of topics $k$ when inspecting models with different number of topics, we relied on two criteria: the statistical fit and robustness of models across different $k$ as well as the interpretability of their topics. ${ }^{3}$ After comparing models with 10 to 200 topics, we settled on a model with $k=38$

\footnotetext{
${ }^{2}$ Articles were prepared for LDA topic modeling by lower case conversion, removal of numbers, punctuation, white space and stop words as well as stemming Feinerer et al. (2008); Grimmer and Stewart (2013); Günther and Quandt (2015). As, based on Zipf's law, we can expect many of the words in our corpus to occur only as rarely as once Li (1992), we decided to trim the corpus by removing words that occurred less than five times.

${ }^{3}$ Statistical fit of a model was indicated though perplexity of models across $k$. Perplexity describes model fit when training the models on training data (75\% of the corpus) and evaluating them on held-out data (25\% of the corpus) (Blei et al., 2003; Jacobi et al., 2015). Robustness of its topics was indicated through topics being stable across different $k$. Interpretability was indicated through coherence and exclusivity of topics, judged based on top terms of each topic across different $k$ Quinn, Monroe, Colaresi, Crespin, and Radev (2010).
} 
topics. This solution indicated both a good statistical fit as well as topics with high internal coherence that are still exclusive when compared to each other.

\section{Step 2: Interpret topic model}

When evaluating the interpretability of topics, researchers typically rely on two measures: the conditional probability $\Phi$ with which a given term in our corpus is likely to occur in a given topic and the conditional probability $\theta$ with which a given topic is likely to occur in a given document (Maier et al., 2018). Based on this information, all 38 topics of our final model now need to be evaluated. To do so, we investigated how well the ten terms with the highest probability for each topic generated a conclusive frame and, similarly, inspected the top ten documents for each topic concerning their suitability (Quinn et al., 2010). We decided to keep 28 out of 38 topics for further analysis that were then labelled and interpreted. 10 topics were detected to be background topics. ${ }^{4}$ Afterwards, we sorted these topics into four overarching themes based on intensive discussions between all authors and their understanding of the topics (see Table 1): "Climate Change Impacts", "Climate Science", "Climate Politics" and "Climate Change and Society".

To assess the occurrence of topics over time concerning RQ3, we assigned articles to topics. While we could also measure the relative importance of topics in all articles over time according to their $\theta$-value, changes in prevalence are easier to understand by assigning each article one topic. As we set $\alpha$ in a way that only few topics would be prevalent in an article, doing so is in line with our model specification. We ascribed each article to the topic for which it had the highest corresponding $\theta$-value, i.e., the topic which is most likely to occur in that article. We made sure topics were assigned with $\theta>.1$ for quality reasons (Günther \&

\footnotetext{
${ }^{4}$ We defined ten topics to be of the theme "Background" (see appendix, Table B). These do not mainly refer to climate change but instead list public events in India, describe awards, school competitions, etc. Though internally consistent, these background topics are not further analyzed here. They are regarded as background noise irrelevant to our analysis concerning the coverage of climate change (Jacobi et al., 2015; Maier et al. (2018); Jacobi, van Atteveldt, and Welbers (2015) given that when selecting articles containing our keyword as seldom as once, we also pick up articles in other contexts which mention these terms only in passing.
} 
Domahidi, 2017). These steps allowed us to eliminate potential noise introduced through sampling.

\section{Step 3: Test reliability and validity of topic model}

Lastly, we tested the reliability and validity of our model. We wanted to make sure that our final model is reliable in the sense that it is robust across parameter specifications (Maier et al., 2018; Roberts, Stewart, \& Tingley, 2016). We therefore analyzed the robustness of our topics when running the model with ten different random seeds (Levy \& Franklin, 2013) and ten different numbers of $k$. One might also be concerned that coverage between both newspapers differs. That is why we checked that our solution stayed stable when running the model separately for articles in either The Hindu or Times of India. Most topics were prevalent in both newspapers. We also had to ensure our model is valid (Grimmer \& Stewart, 2013), i.e., that external coders would assign the same meaning to our topics. That is why four project-external coders tested whether a topic is semantically coherent and whether the assignment of topics to documents made sense (Chang, Gerrish, Wang, Boyd-Graber, \& Blei, 2009) (for more information on all tests, see Table A in the appendix).

\section{Results}

RQ1: How Salient Was Climate Change in Indian Media from 1997 to 2016?

Climate change coverage in India has increased substantially over the past 20 years (see Figure 1). Overall, articles dealing with climate change account for 0.33 percent of the entire coverage of the analyzed newspaper.

Figure 1. The Share of Climate Change Media Coverage in Times of India and Hindu from 1997 to 2016 


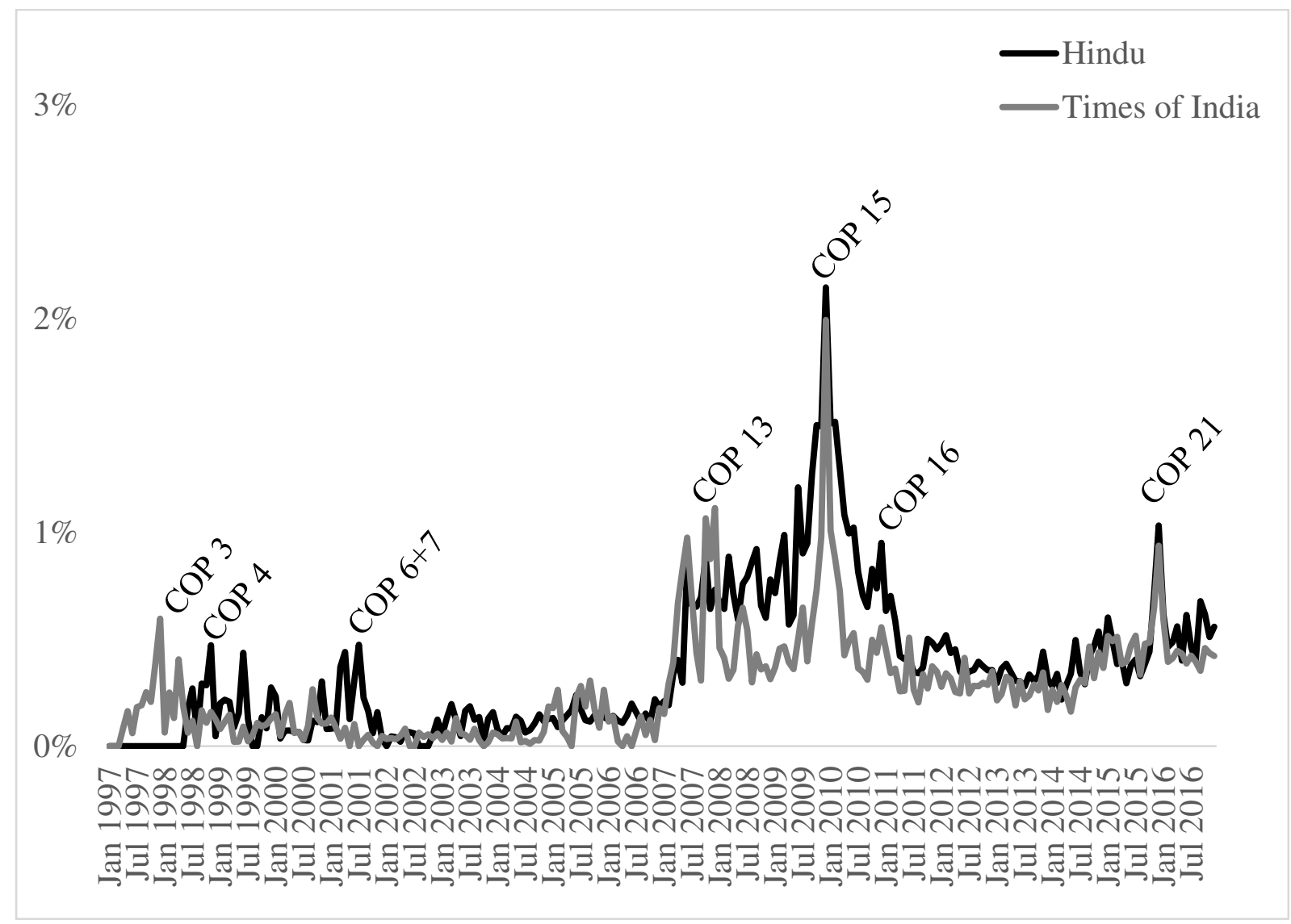

Most peaks of the climate change media coverage correspond with COP meetings (M. Boykoff, 2010; Schäfer \& Schlichting, 2014; Schmidt et al., 2013). The first small peaks of climate change media coverage correspond with the COP meetings in the years 1997 (COP 3), 1998 (COP 4), and 2001 (COP 6 \& 7) and made up roughly a half percent of all The Hindu's and Times of India's news coverage. After having lost its attraction for the media from 2002 until the end of 2006, the topic gained traction in both newspapers from 2007 onwards, particularly in June 2007, when the Prime Minister's Council on Climate Changes was formed, and reached the one percent mark for the first time around COP 13 in Bali in 2007. The next peak in media coverage corresponded to COP 15 in Copenhagen in 2009, when climate change again gained media traction: During these events, climate change news accounted for around two percent of all news coverage in both newspapers. Although the amount of coverage decreased afterwards, it was still reported on more often from 2011 until 
2015 than in the first ten years (e.g., during the COP 16). Climate change coverage reached its (so far) last peak in December 2015 around the COP 21 in Paris.

RQ2: Which Themes and Topics Can Be Identified?

Aside from background topics, we identified 28 climate change-related topics within the article corpus, which we organized into four overarching themes: "Climate Change Impacts", "Climate Science", "Climate Politics", and "Climate Change and Society" (see Table 1). 
Table 1. Themes and topics within climate change coverage in India, $N=18,244$

\begin{tabular}{|c|c|c|c|c|}
\hline$k$ & Label & $\begin{array}{l}\text { Average } \\
\text { probability } \\
(\mathrm{SD})\end{array}$ & $\begin{array}{l}\text { Occurrence } \\
\text { (\% of articles } \\
\text { in corpus) }\end{array}$ & Top-5 Terms \\
\hline \multicolumn{5}{|c|}{ Theme: "Climate Change Impacts" } \\
\hline 20 & Agriculture & $3.4 \%(.99)$ & $915(5.02 \%)$ & agricultur, farmer, crop, food, product \\
\hline 31 & Weather changes & $3.7 \%(.12)$ & $680(3.73 \%)$ & temperatur, year, degre, rain, rainfal \\
\hline 18 & Water scarcity & $2.1 \%(.07)$ & $395(2.17 \%)$ & water, river, flood, resourc, dam \\
\hline 26 & Sea level rise & $1.9 \%(.07)$ & $360(1.97 \%)$ & sea, coastal, fish, island, rise \\
\hline 25 & Animals & $1.6 \%(.07)$ & $335(1.84 \%)$ & bird, wildlif, anim, tiger, forest \\
\hline 38 & Biodiversity & $1.8 \%(.06)$ & $322(1.76 \%)$ & $\begin{array}{l}\text { speci, biodivers, conserv, plant, } \\
\text { research }\end{array}$ \\
\hline 35 & Forests & $2 \%(.06)$ & $307(1.68 \%)$ & forest, land, area, conserv, environ \\
\hline 2 & Melting glaciers & $1.5 \%(.06)$ & $277(1.52 \%)$ & glacier, ice, melt, himalayan, arctic \\
\hline \multicolumn{5}{|c|}{ Theme: "Climate Science" } \\
\hline 17 & $\begin{array}{l}\text { Scientific research } \\
\text { on the impacts of } \\
\text { climate change }\end{array}$ & $3.6 \%(.08)$ & $582(3.19 \%)$ & climat, chang, impact, report, disast \\
\hline 30 & $\begin{array}{l}\text { Scientific } \\
\text { measurements of } \\
\text { climate change }\end{array}$ & $2.5 \%(.08)$ & $472(2.59 \%)$ & studi, research, climat, scientist, ocean \\
\hline \multicolumn{5}{|c|}{ Theme: "Climate Politics" } \\
\hline 36 & $\begin{array}{l}\text { International } \\
\text { summits }\end{array}$ & $5.01 \%(.15)$ & $\begin{array}{l}1,160 \\
(6.36 \%)\end{array}$ & countri, climat, develop, india, chang \\
\hline 13 & Energy conservation & $2.83 \%(.08)$ & $630(3.45 \%)$ & energi, power, solar, renew, electr \\
\hline 21 & Project funding & $3.9 \%(.08)$ & $618(3.39 \%)$ & project, state, plan, govern, crore \\
\hline 4 & $\begin{array}{l}\text { Economic } \\
\text { sustainability }\end{array}$ & $2.8 \%(.07)$ & $477(2.61 \%)$ & $\begin{array}{l}\text { india, develop, compani, technolog, } \\
\text { industri }\end{array}$ \\
\hline 16 & Emission reduction & $2.7 \%(.07)$ & $419(2.3 \%)$ & $\begin{array}{l}\text { carbon, emiss, global, greenhous, } \\
\text { reduc }\end{array}$ \\
\hline 7 & Regional summits & $2.15 \%(.06)$ & $238(1.3 \%)$ & countri, world, south, intern, summit \\
\hline 1 & Nuclear politics & $1.08 \%(.05)$ & $167(0.92 \%)$ & nuclear, india, energi, power, franc \\
\hline \multicolumn{5}{|c|}{ Theme: "Climate Change and Society" } \\
\hline 15 & $\begin{array}{l}\text { Workshops on } \\
\text { climate change }\end{array}$ & $4.38 \%(.1)$ & $844(4.63 \%)$ & organ, chang, climat, inaugur, director \\
\hline 32 & $\begin{array}{l}\text { Society awareness } \\
\text { campaigns }\end{array}$ & $4.35 \%(.09)$ & $734(4.02 \%)$ & develop, india, world, countr, sustain \\
\hline 33 & $\begin{array}{l}\text { Earth hour } \\
\text { campaign }\end{array}$ & $3.45 \%(.1)$ & $694(3.8 \%)$ & earth, campaign, awar, people, hour \\
\hline 11 & University programs & $3.01 \%(.08)$ & $612(3.35 \%)$ & $\begin{array}{l}\text { univers, scienc, research, student, } \\
\text { institut }\end{array}$ \\
\hline 29 & Student trainings & $2.78 \%(.08)$ & $485(2.66 \%)$ & nadu, tamil, chennai, organ, colleg \\
\hline 24 & Planting & $2.27 \%(.07)$ & $461(2.53 \%)$ & tree, plant, sapl, green, district \\
\hline 34 & Transportation & $2.16 \%(.06)$ & $336(1.84 \%)$ & citi, road, urban, transport, vehicl \\
\hline 19 & Pollution & $2 \%(.06)$ & $310(1.7 \%)$ & pollut, wast, environ, environment, air \\
\hline 37 & Health & $1.4 \%(.06)$ & $241(1.32 \%)$ & health, diseas, peopl, caus, increas \\
\hline 27 & Science express & $1.6 \%(.08)$ & $216(1.18 \%)$ & scienc, exhibit, train, express, railway \\
\hline 5 & Green buildings & $1.48 \%(.05)$ & $211(1.16 \%)$ & build, green, use, design, hous \\
\hline
\end{tabular}

Notes: Primary topic assignment was based on the highest $\theta$-value over different topics for each document (threshold >.1). We display both the average probability of topic occurrence across all articles (second column) 
and articles assigned to this topic as their main topic (third column). All top 5 terms (fifth column) are shown in their stemmed form (e.g., "agricultur" could have been derived from the words "agricultural" or "agriculture").

Under the theme "Climate Change Impacts", eight topics were subsumed. Most popular among those is Agriculture with a frequency of 5.02\% of all articles displaying this topic as their main topic. In the respective articles, climate change impacts on crop yields are highlighted, with some of them informing farmers about adaptation to different or new crops. A practical concern related to climate change is expressed through Weather changes $(3.73 \%)$ describing the high variability of temperature and rainfall patterns in India. Endangerment is an argumentative line that pervades Indian coverage of climate change: From Water scarcity $(2.17 \%)$, to threats to wildlife (Animals, $1.84 \%)$, flowers and fungi (Biodiversity, $1.76 \%$ )*5, Forests (1.68\%), oceanic life and coastlines (Sea level rise, 1.97\%), and the meltdown of glaciers (Melting glaciers, 1.52\%).

In the context of the theme "Climate Science", climate change is presented through the lens of scientific studies and measurement techniques in two topics: Articles discussing Scientific research on the impacts of climate change (3.19\%) report the harmful impacts of climate change as they appear in IPCC assessments or corrected models illustrating effects of climate change appearing earlier than previously estimated. Another topic stresses new technologies to monitor and mitigate climate change, e.g., satellites to better understand climate change impacts in India or innovative mitigation techniques such as increasing the reflectivity of clouds to cool the earth (Scientific measures of climate change, 2.59\%). Further, these stories present climate change as real, human-caused, with impacts already visible in India and elsewhere. Articles connected to this topic extensively cite scientists or scientific associations' reports such as the IPCC assessments and suggest robust scientific

\footnotetext{
5 This topic is one of the three topics that show low validity and robustness and should hence be considered with caution (for details see Table A in the appendix). This topic specifically merges with Forests and Animals in further robustness tests and is therefore not clearly distinguishable. We marked the three topics that scored low both on validity and robustness measures with an asterisk.
} 
evidence about climate change. For example, a report in The Hindu about the release of fourth IPCC assessment in September 2007 quoted Professor Parry, co-chairman of the IPCC working group: "We are all used to talking about these impacts coming in the lifetimes of our children and grandchildren. Now we know that it's us" (Adam, 2007).

Seven further topics were categorized into the theme "Climate Politics". The respective coverage is driven by political events: International summits (6.36\%), for example in Paris or Kyoto, cause further reportage on climate change. Articles assigned to this topic highlight the traditional positions of India on differentiated responsibility between the developed and developing countries, funding and technology transfer, and the associated political battles between the US and other developed countries on the one hand, and India and developing countries on the other. Nevertheless, topics also focus on regional or national policy making on climate change: These include national decision making on how the government is switching to more sustainable forms of energy production by, for example, shifting to LED light bulbs, and increasing adoption of solar power (Energy conservation, $3.45 \%)$. Some of the stories are critical about the slow pace of adoption when it comes to alternative energy sources ("Escoms [electricity supply companies] fail to meet solar power purchase target," The Hindu, 2014). A further domestication of climate politics is reported through Project funding (3.39\%), where the newspapers describe the federal and state governments' funding of climate action plans. This aspect is also expressed through Economic sustainability $(2.61 \%)^{*}$, a topic describing private organizations' engagement with or investment in sustainable projects. Also, Emission reduction (2.3\%) highlights efforts to reduce current or future emissions through adoption of clean development mechanism (CDM) projects and carbon credits ("Metro to take advantage of Kyoto Protocol, trade carbon bonds" Belgaumkar, 2007). In addition, the topic Regional summits (1.3\%) describes conferences with for example BRIC (Brazil, Russia, India and China) countries and Nuclear politics $(.92 \%)$ specifies debates about nuclear energy policy, particularly about nuclear deals with the 
US and France. In sum, these topics show how climate change is related to national and international politics and policies on a macro and meso level.

Lastly, eleven topics describing broader societal impacts of climate change and awareness programs, subsumed here under "Climate Change and Society", make up for the biggest overarching theme. These often address Indian citizens directly by reporting on how individuals encounter and are affected by climate change, and ways to mitigate and adapt in their daily lives. Most of these topics are strongly event-driven: Both The Hindu and Times of India heavily cover possibilities of engaging with the issue of climate change: from reporting about seminars, workshops or congresses (Workshops on climate change, 4.63\%), participation in the global Earth hour campaign (3.8\%), and more broadly Society awareness campaigns $(4.02 \%)^{*}$, expressed through the description of shared global problems such as poverty, inequality or starvation to underline the need for shared values and collective consciousness when it comes to protecting the planet. Students are a primary focus of coverage in the form of University programs (3.35\%) or Student trainings (2.66\%) on campus to temporal campaigns created to gain public attention and create awareness. Other public engagement programs include Planting (2.53\%) saplings and the Science express $(1.18 \%)$, an initiative by the Indian government to educate the public on environmental issues by exhibiting scientific advancements in a train that visits various parts of the country. Finally, Green buildings $(1.16 \%)$ illustrate how remodeling houses using sustainable materials might have a positive effect. Domestic challenges are further highlighted through focus on need for better and efficient Transportation (1.84\%) systems and policies, Pollution $(1.7 \%)$, which highlights the harm caused by inefficient waste disposal, particularly burning or dumping waste resulting in the emission of greenhouse gases, and an increase of infectious diseases due to climate change (Health, 1.32\%). All these topics address the readers on an individual, almost personal level, to raise awareness for climate change and explain citizens how they can contribute to fighting a global challenge in their daily lives. 
RQ3: How Prevalent Were These Themes and Topics between 1997 and 2016?

To illustrate temporal changes, this study sheds light on how coverage within the four overarching themes - "Climate Change and Society", "Climate Politics", "Climate Change Impacts", and "Climate Science" - has developed over time. While Figure 2 illustrates the absolute number of articles related to these themes between 1997 and 2016, Figure 3 describes the percentage of articles any theme accounts for in relation to the corpus within a given year.

Figure 2. Absolute occurences by overarching theme

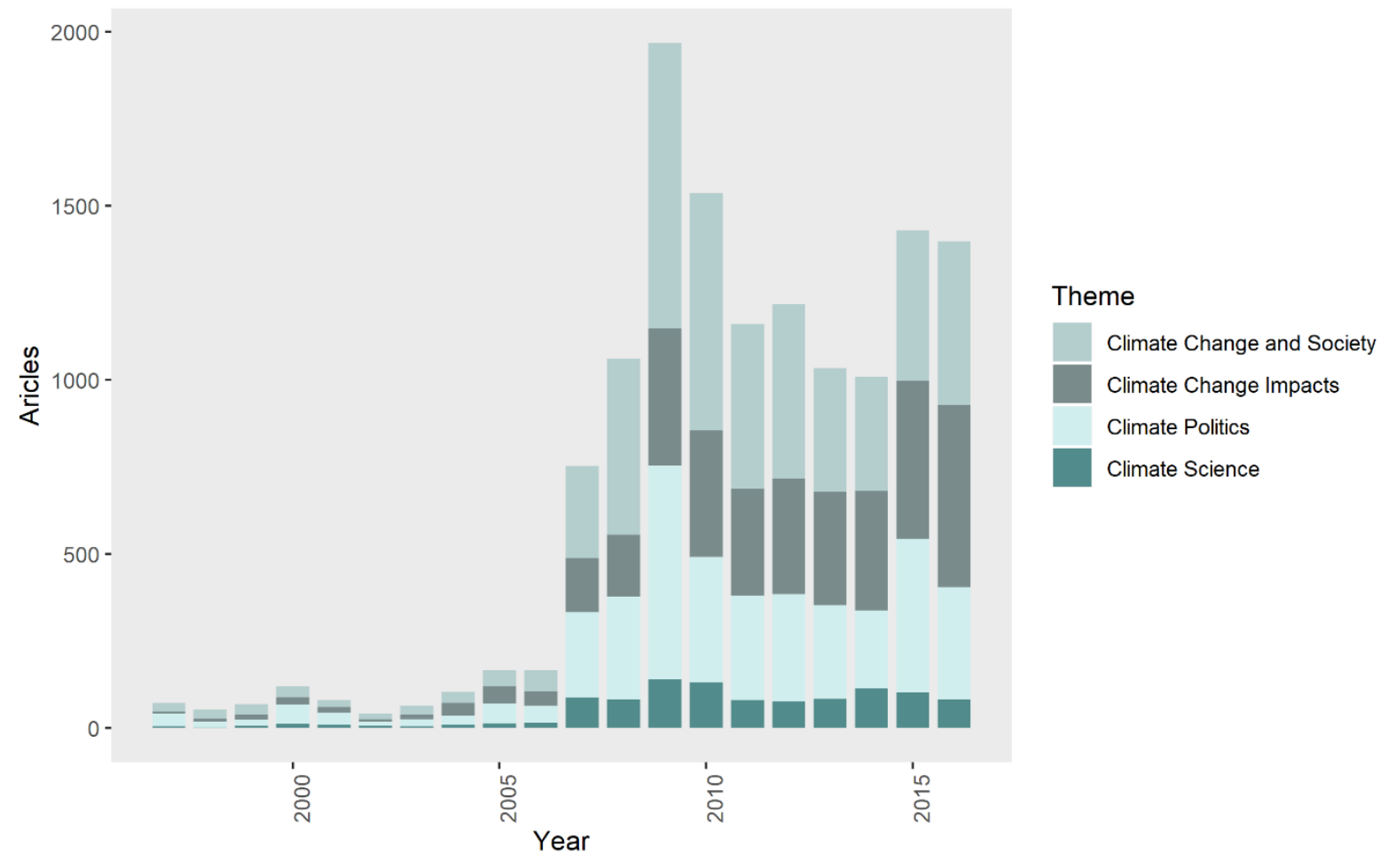


Figure 3. Percentage of total coverage by overarching theme

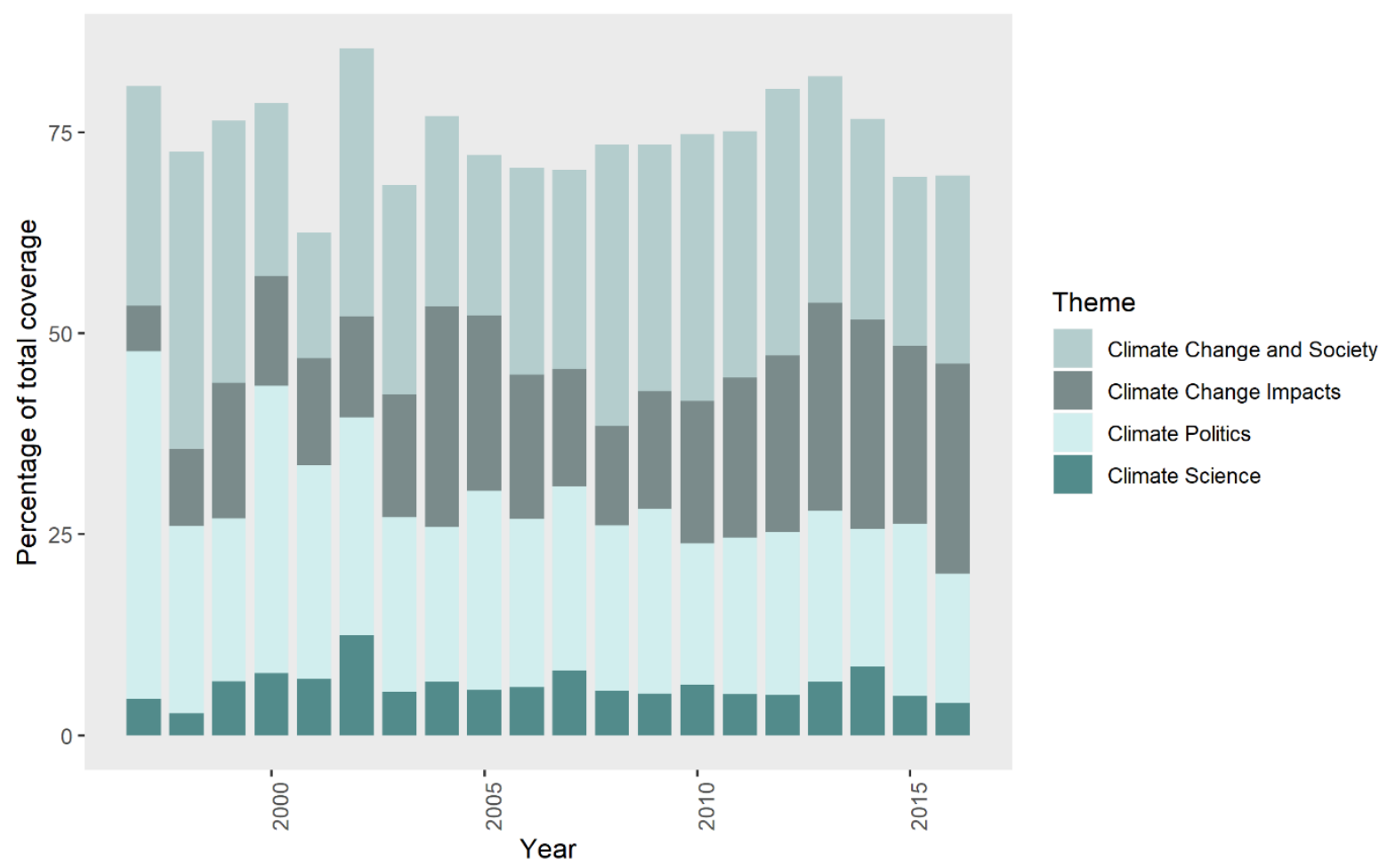

Note: Percentages do not sum up to 100 percent due to the omission of background topics.

As already mentioned concerning RQ1, coverage has generally increased since 2007.

However, the context within which climate change is discussed has changed over time. The theme "Climate Change and Society" made up the biggest part of climate change coverage throughout most years $(M=27.37 \%, S D=5.69)$. The theme received increased attention since 2008 due to different climate change awareness campaigns, foremost the Earth Hour Campaign, but also university programs being reported on more heavily. However, attention to this theme has slightly decreased in recent years. As topics related to this theme are very event driven, e.g., the Earth hour campaign or other Society awareness campaigns, the yearly composition of topics driving this theme varies heavily (for detailed information on temporal development within the four themes see appendix, Figure B-I). Hence, the way Indian media discuss how individuals are affected and might learn about climate change in their daily life changes over time. Throughout years, second most articles focused on "Climate Politics" ( $M$ 
$=23.12 \%, S D=6.38)$, a theme that has received slightly less attention over time. However, the occurrence of this theme is volatile due to its dependence on international summits on climate change. It is mainly two topics that show high volatility within this theme: While the topic International summits is driven by political events and therefore appears more often in some years than others, the topic Emission has lost importance over time. A theme that is still relatively frequently reported on is "Climate Change Impacts" $(M=17.75 \%, S D=6.01)$. This theme and topics connected to it have seen increased media attention in recent years.

Coverage of issues such as Animals, Forests and Water scarcity has almost doubled between 2007 (14.57\%) and 2016 (26.1\%). In comparison, fewer articles were written on "Climate Science" $(M=6.24 \%, S D=2.03)$, for which its average occurrence stayed relatively stable over time.

In conclusion, the context in which climate change is being reported on by Indian news media is mainly societal or political and there is less focus on environmental impacts of climate change or climate science. However, especially environmental issues such as the protection of wildlife, forests or the increasing shortage of water have become a more prominent issue in Indian coverage recently.

\section{Discussion and Conclusion}

Based on the largest study of Indian media coverage of climate change to date, we have shown that climate change-related media coverage in India has increased substantially over the past twenty years - albeit it still lags considerably behind the average amount of media attention in other countries, which was approximately twice as high as in India ( $0.6 \%$ to $0.3 \%$, see Schmidt et al., 2013, p. 1241).

In terms of topics and themes, we identified four overarching themes our 28 topics were subsumed into: "Climate Change Impacts", "Climate Science", "Climate Politics" and "Climate Change and Society". Results show that Indian media substantially report on a wide range of 
climate change impacts, which appear to be increasing in frequency compared to other themes. Impacts related to agriculture are covered most frequently, in alignment with the high sensitivity of agriculture to climate impacts-agriculture employs about 50 percent of the workforce in India and over $50 \%$ of net sown area rely completely on annual rainfall season without access to irrigation (Economic Survey, 2018). Mirroring other key vulnerability sectors in India, newspapers highlight climate change impacts related to weather changes, water scarcity, animals, biodiversity, and glaciers. Sea level rises are another consistently reported impact, probably because India has over 7,000 kilometers of coastline where megacities such as Mumbai, Chennai, and Kolkata are located.

Indian media not only cover scientific research on the negative impacts of climate change but also highlight, in equal measure, scientific advancements to help better understand climate change, and ways to mitigate and adapt. Scientists and scientific organizations are prominent sources covered in such stories, and these stories present climate change as real, human-caused, and with negative impacts already visible in India and elsewhere, reiterating previous findings (e.g. Billett, 2010; Painter \& Ashe, 2012). The coverage of climate science stories, however, has remained consistently low compared to other topics. This is possibly due to the science of climate change being perceived as largely settled in the Indian press, different from Anglophone countries where coverage has been shown to be more indecisive (Painter $\&$ Ashe, 2012). It is also possible that the science coverage is low because of a lack of scientific expertise in the Indian media organizations (Acharya \& Noronha, 2010).

Climate politics form another substantial part of Indian media coverage. International summits on climate change dominate Indian media coverage of climate change politics, a finding similarly reported by other studies (Jogesh, 2012; Schäfer et al., 2013). Coverage on international summits highlights Indian government's key positions in terms of differentiated responsibility for action, technology and funds transfer to developing countries, and only voluntary reductions by developing countries such as India (Billett, 2010). Different from other 
studies, however, we show that regional summits on climate change and bilateral nuclear agreements are also covered widely, indicating that the importance of climate change is not only a global, but also a regional and national issue. While some scholars argue that Indian media frame climate change along divided lines of developed versus developing countries in a "largely hackneyed and arguably unproductive discourses along a risk-responsibility divide" (M. Boykoff, 2010, p. 24; cf. Billett, 2010; Schmidt \& Schäfer, 2015), others argue that the discourse about domestic responsibility and action is shifting (Jogesh, 2012; Lück et al., 2016; Mittal, 2012; Olausson, 2014). Our study shows that while international summits stories which highlight the fundamental positions of India about equity and differentiation - dominate news media coverage concerning climate politics, there is an increasing "domestication" (Eide, Kunelius, \& Kumpu, 2010; cf. Hellsten, Porter, \& Nerlich, 2014) of the climate change issue through a focus on project funding of federal and state action plans on climate change, along with policies and practices related to energy reduction, conservation, and economic sustainability.

A novel and perhaps the most important finding of this study is the individualization of coverage (cf. Koteyko, 2010), i.e., the myriad ways in which the Indian media expose and potentially educate the Indian public about climate change. Reporting on climate change based on its individual effects and possibilities of acquiring knowledge about the issue is by far the most prevalent context of discussing climate change in the Indian coverage. The high prevalence of different education avenues is expressed through workshops on climate change, university programs, student trainings, society awareness campaigns, science express, and the global Earth Hour campaign. Further, through reporting on local environmental and climate change challenges such as pollution, infrastructure issues such as transportation and green buildings, Indian media provide avenues for the Indian public to understand and contextualize the complex phenomenon. This appears to be particularly important as a majority of Indians report little or no knowledge about climate change (Leiseriowitz \& Thaker, 2012). 
Overall, we find that topics related to "Climate Change and Society" as well as "Climate Politics" are, on average, covered more frequently throughout the years than "Climate Change Impacts" and especially "Climate Science" which are rarely included in coverage. While the occurrence of all themes varies throughout the years, coverage on "Climate Change Impacts", e.g., on animals or forests, has almost doubled between 2007 and 2016.

There are limitations to this study. First, while we selected two highly popular English newspapers in India, future studies should include other English-language newspapers such as The Indian Express and the Hindustan Times, even though previous studies found little difference in climate change coverage between those newspapers (Billett, 2010; Jogesh, 2012; Mittal, 2012) probably due to a lack of domestic politicization of the issue. Second, our sampling approach was based on single occurrences of predefined keywords, resulting in articles only mentioning climate change in passing being included in our sample and consequently background topics. While our sampling strategy follows widely shared procedures in the field (Schmidt et al., 2013), using sharper identification criteria, for example more specific search terms, might improve future studies. The assignment of one prevalent topic to an article has to be considered with caution: Although we used a predefined threshold for identification, an article will never consist of only one topic. Future topics might therefore either assign more than one topic to an article setting the threshold higher than the one used here. They might also consider dynamic topic models (Blei \& Lafferty, 2006) to allow for topics to change over time or include the articles details' such as whether it was published above the fold, on the front page, or at the end of a newspaper. In addition, the sorting of topics into overarching themes was done manually based on the authors' discussion of the content of these articles which might be accompanied and verified by automated procedures (Maier et al., 2018). We also found that some topics are less robust, occur only in either one of the newspapers and are harder to validate by external reviewers which challenges their significance for this study. 
Eventually, a large-scale analysis such as ours will always be limited in terms of indepth descriptions of the phenomenon under analysis, for example, which specific events trigger increased media coverage. In turn, it has other advantages. While previous studies had narrower analytical foci, our comprehensive 20-year coverage illustrates that media attention for climate change in India has increased substantially, that various topics were covered in the Indian press, and that some of them gained importance over time. Importantly, we find an increasing domestication and individualization of climate change reporting, presenting the issue as more pressing to Indians and showing them more ways of taking action - potentially helping to educate, organize, and agitate Indians in order to further ambitious action on climate change. 


\section{References}

Acharya, K., \& Noronha, F. (2010). The green pen: Environmental journalism in India and South Asia. New Delhi: SAGE.

Adam, D. (2007, September 20). How climate change will affect the world. The Hindu, p. 1.

Arlt, D., Hoppe, I., \& Wolling, J. (2011). Climate change and media usage: Effects on problem awareness and behavioural intentions. International Communication Gazette, 73(1-2), 45-63. https://doi.org/10.1177/1748048510386741

Audit Bureau of Circulations (2018). http://www.auditbureau.org/index.html

Belgaumkar, G.D. (2007, August 21). Metro to take advantage of Kyoto Protocol, trade carbon bonds. The Hindu, p. 1 .

Billett, S. (2010). Dividing climate change: Global warming in the Indian mass media. Climatic Change, 99(1-2), 1-16. https://doi.org/10.1007/s10584-009-9605-3

Blei, D. M., \& Lafferty, J. D. (2006). Dynamic topic models. Proceeding ICML '06 Proceedings of the 23rd International Conference on Macine Learning, 113-120. Retrieved from https://dl.acm.org/citation.cfm?id=1143859

Blei, D. M. (2012). Probabilistic topic models. Communications of the ACM, 55(4), 77. https://doi.org/10.1145/2133806.2133826

Blei, D. M., Ng, A. Y., \& Jordan, M. I. (2003). Latent Dirichlet Allocation. Journal of Machine Learning Research, 3, 993-1022.

Boykoff, M. (2010). Indian media representations of climate change in a threatened journalistic ecosystem. Climatic Change, 99(1-2), 17-25. https://doi.org/10.1007/s10584010-9807-8

Boykoff, M. T., \& Boykoff, J. M. (2004). Balance as bias: Global warming and the US prestige press. Global Environmental Change, 14(2), 125-136.

https://doi.org/10.1016/j.gloenvcha.2003.10.001

Boykoff, M. T., Daly, M., McAllister, L., McNatt, M., Nacu-Schmidt, A., Oonk, D., \& Pearman, O. (2018). Indian Newspaper Coverage of Climate Change or Global Warming, 2000-2018. Retrieved from http://sciencepolicy.colorado.edu/media_coverage

Boykoff, M. T., \& Goodman, M. K. (2009). Conspicuous redemption?: Reflections on the promises and perils of the 'Celebritization' of climate change. Geoforum, 40(3), 395-406. https://doi.org/10.1016/j.geoforum.2008.04.006

Brossard, D., Shanahan, J., \& McComas, K. (2004). Are Issue-Cycles Culturally Constructed?: A Comparison of French and American Coverage of Global Climate Change. Mass Communication and Society, 7(3), 359-377. https://doi.org/10.1207/s15327825mcs0703_6

Brüggemann, M., \& Engesser, S. (2017). Beyond false balance: How interpretive journalism shapes media coverage of climate change. Global Environmental Change, 42, 58-67. https://doi.org/10.1016/j.gloenvcha.2016.11.004

Büchi, M. (2017). Microblogging as an extension of science reporting. Public Understanding of Science (Bristol, England), 26(8), 953-968. https://doi.org/10.1177/0963662516657794

Bureau, E. T. (2014, May 28). Ministry of environment and forests undergoes a nomenclature change; government serious to tackle climate change. The Economic Times. Retrieved from https://economictimes.indiatimes.com/news/economy/policy/ministry-of- 
environment-and-forests-undergoes-a-nomenclature-change-government-serious-to-tackleclimate-change/articleshow/35651292.cms

Carmichael, J. T., \& Brulle, R. J. (2016). Elite cues, media coverage, and public concern: An integrated path analysis of public opinion on climate change, 2001-2013. Environmental Politics, 26(2), 232-252. https://doi.org/10.1080/09644016.2016.1263433

Carvalho, A. (2007). Ideological cultures and media discourses on scientific knowledge: Rereading news on climate change. Public Understanding of Science, 16(2), 223-243. https://doi.org/10.1177/0963662506066775

Carvalho, A. (2010). Media(ted)discourses and climate change: A focus on political subjectivity and (dis)engagement. Wiley Interdisciplinary Reviews: Climate Change, 1(2), 172-179. https://doi.org/10.1002/wcc.13

Chang, J., Gerrish, S., Wang, C., Boyd-Graber, J., \& Blei, D. M. (2009). Reading Tea Leaves: How Humans Interpret Topic Models. Retrieved from https://papers.nips.cc/paper/3700reading-tea-leaves-how-humans-interpret-topic-models.pdf

DARA. (2012). Climate Vulnerability Monitor: A Guide to the Cold Calculus of a Hot Planet. Retrieved from https://daraint.org/wp-content/uploads/2012/10/CVM2-Low.pdf

Dubash, N. K., Khosla, R., Rao, N. D., \& Bhardwaj, A. (2018). India's energy and emissions future: an interpretative analysis of model scenarios. Environmental Research Letters. Retrieved from http://iopscience.iop.org/article/10.1088/1748-9326/aacc74

Dubash, N. K. (Ed.). (2012). Handbook of climate change and India: Development, politics, and governance. London: Earthscan.

Economic Survey. (2018). Economic Survey 2017-18: Climate, climate change, and agriculture. Retrieved from https://www.thehindu.com/business/budget/article22550000.ece/BINARY/Chapter6

Eide, E., Kunelius, R., \& Kumpu, V. (2010). Global climate-local journalisms: A Transnational Study of how Media make Sense of Climate Summits. Projektverlag.

Feinerer, I., Hornik, K., \& Meyer, D. (2008). Text Mining Infrastructure in R. Journal of Statistical Software, 25(5). https://doi.org/10.18637/jss.v025.i05

Figueres, C., Schellnhuber, H. J., Whiteman, G., Rockström, J., Hobley, A., \& Rahmstorf, S. (2017). Three years to safeguard our climate. Retrieved from https://www.nature.com/news/three-years-to-safeguard-our-climate-1.22201

Griffiths, T. L., Steyvers, M., \& Tenenbaum, J. B. (2007). Topics in Semantic Representation. Psychological Review, 114(2), 211-244. doi: 10.1037/0033-295X.114.2.211

Grimmer, J., \& Stewart, B. M. (2013). Text as Data: The Promise and Pitfalls of Automatic Content Analysis Methods for Political Texts. Political Analysis, 21(03), 267-297. https://doi.org/10.1093/pan/mps028

Grün, B., \& Hornik, K. (2011). topicmodels: An R Package for Fitting Topic Models. Journal of Statistical Software, 40(13). https://doi.org/10.18637/jss.v040.i13

Günther, E., \& Domahidi, E. (2017). What communication scholars write about: An analysis of 80 years of research in high-impact journals. International Journal of Communication, $11,3051-3071$.

Günther, E., \& Quandt, T. (2015). Word Counts and Topic Models. Digital Journalism, 4(1), 75-88. https://doi.org/10.1080/21670811.2015.1093270 
Gupta, S. (2003). Implementing Kyoto-Type Flexibility Mechanisms for India: Problems and Prospects. OECD Headquarters, Paris 17-18 March, 2003. Retrieved from http://www.oecd.org/env/cc/2957638.pdf

HDR. (2016). Human Development Report. Retrieved from http://report.hdr.undp.org/

Hellsten, I., Porter, A. J., \& Nerlich, B. (2014). Imagining the future at the global and national scale: a comparative study of British and Dutch press coverage of Rio 1992 and Rio 2012. Environmental Communication, 8, 468-488.

Hijioka, Y., Lin, E., Pereira, J. J., Corlett, R. T., Cui, X., Insarov, G. E., . . Surjan, A. (2014). Asia: Climate Change 2014: Impacts, Adaptation, and Vulnerability. Part B: Regional Aspects. Contribution of Working Group II on the Fifth Assessment Report of the Intergrovernmental Panel on Climate Change. Retrieved from https://www.ipcc.ch/pdf/assessment-report/ar5/wg2/WGIIAR5-Chap24_FINAL.pdf

IEA. (2013). International Energy Agency2013: Annual Report. Retrieved from https://www.iea.org/publications/freepublications/publication/2013_AnnualReport.pdf

IPCC. (2013). Climate Change 2013: The Physical Science Basis. Retrieved from http://www.ipcc.ch/report/ar5/wg1/

Ivanova, A. (2015). Transnationalisierung von Öffentlichkeiten (Dissertation). Springer Fachmedien Wiesbaden GmbH.

Jacobi, C., van Atteveldt, W., \& Welbers, K. (2015). Quantitative analysis of large amounts of journalistic texts using topic modelling. Digital Journalism, 4(1), 89-106. https://doi.org/10.1080/21670811.2015.1093271

Jaiswal, A. (2017). India leads on climate action as Trump exits Paris Agreement. Retrieved from https://www.nrdc.org/experts/india-leads-climate-action-trump-withdraws-paris

Jasanoff, S. (1993). India at the crossroads in global environmental policy. Global Environmental Change, 3(1), 32-52. https://doi.org/10.1016/0959-3780(93)90013-B

Jogesh, A. (2012). A change in climate? Trends in climate change reportage in the Indian print media. In N. Dubash (Ed.), Handbook of climate change and India: Development, politics and governance (pp. 266-286). New York, New York, USA: Earthscan.

Kirilenko, A. P., \& Stepchenkova, S. O. (2012). Climate change discourse in mass media: Application of computer-assisted content analysis. Journal of Environmental Studies and Sciences, 2(2), 178-191. https://doi.org/10.1007/s13412-012-0074-z

Koteyko, N. (2012). Managing carbon emissions: a discursive presentation of "market-driven sustainability" in the British media. Language \& Communication, 32, 24-35.

Lee, T. M., Markowitz, E. M., Howe, P. D., Ko, C.-Y., \& Leiserowitz, A. A. (2015). Predictors of public climate change awareness and risk perception around the world. Nature Climate Change, 5(11), 1014-1020. https://doi.org/10.1038/nclimate2728

Levy, K. E. C., \& Franklin, M. (2013). Driving Regulation. Social Science Computer Review, 32(2), 182-194. https://doi.org/10.1177/0894439313506847

Li, W. (1992). Random texts exhibit Zipf's-law-like word frequency distribution. IEEE Transactions on Information Theory, 38(6), 1842-1845. https://doi.org/10.1109/18.165464

Liu, X., Lindquist, E., \& Vedlitz, A. (2011). Explaining Media and Congressional Attention to Global Climate Change, 1969-2005: An Empirical Test of Agenda-Setting Theory. Political Research Quarterly, 64(2), 405-419. https://doi.org/10.1177/1065912909346744 
Lück, J., Wessler, H., Wozniak, A., \& Lycarião, D. (2016). Counterbalancing global media frames with nationally colored narratives: A comparative study of news narratives and news framing in the climate change coverage of five countries. Journalism: Theory, Practice \& Criticism, 14(3), 146488491668037. https://doi.org/10.1177/1464884916680372

Maier, D., Waldherr, A., Miltner, P., Wiedemann, G., Niekler, A., Keinert, A., . . Adam, S. (2018). Applying LDA topic modeling in communication research: Toward a valid and reliable methodology. Communication Methods and Measures, 54(10), 1-26. https://doi.org/10.1080/19312458.2018.1430754

Mittal, R. (2012). Climate Change Coverage in Indian Print Media: A Discourse Analysis. The International Journal of Climate Change: Impacts and Responses, 3(2), 219-232. Retrieved from http://hdl.handle.net/1959.14/181299

Moser, S. C. (2010). Communicating climate change: History, challenges, process and future directions. Wiley Interdisciplinary Reviews: Climate Change, 1(1), 31-53. https://doi.org/10.1002/wcc.11

NAPCC. (2008). National Action Plan on Climate Change. Retrieved from http://www.moef.nic.in/downloads/home/Pg01-52.pdf

Nisbet, M. C. (2009). Communicating Climate Change: Why Frames Matter for Public Engagement. Environment: Science and Policy for Sustainable Development, 51(2), 1223. https://doi.org/10.3200/ENVT.51.2.12-23

Olausson, U. (2014). The Diversified Nature of "Domesticated" News Discourse. Journalism Studies, 15(6), 711-725. https://doi.org/10.1080/1461670X.2013.837253

Painter, J. (2011). Poles Apart: The International Reporting of Climate Scepticism. Retrieved from https://reutersinstitute.politics.ox.ac.uk/sites/default/files/research/files/Poles\%2520Apart $\% 2520$ the \%2520international\%2520reporting\%2520of\%2520climate\%2520scepticism.pdf

Painter, J. (2014). Disaster Averted? Televison Coverage of the 2013/14 IPCC's Climate Change Reports. Retrieved from https://ora.ox.ac.uk/objects/uuid:1a34998e-407b-4c06a9df-

9d8a934ca249/download_file?file_format=pdf\&safe_filename=Television $\% 2 B C o v e r a g e \%$ 2Bof\%2Bthe\%2B2013\%252F14\%2BIPCC\%25E2\%2580\%2599s\%2BClimate\%2BChange $\%$ 2BReports\&type_of_work=Report

Painter, J., \& Ashe, T. (2012). Cross-national comparison of the presence of climate scepticism in the print media in six countries, 2007-10. Environmental Research Letters, 7(4), 44005. https://doi.org/10.1088/1748-9326/7/4/044005

Quinn, K. M., Monroe, B. L., Colaresi, M., Crespin, M. H., \& Radev, D. R. (2010). How to Analyze Political Attention with Minimal Assumptions and Costs. American Journal of Political Science, 54(1), 209-228. https://doi.org/10.1111/j.1540-5907.2009.00427.x

R Development Core Team. (2017). R: A language and environment for statistical computing. $\mathrm{R}$ foundation for statistical computing. Vienna, Austria. Retrieved from http://www.Rproject.org

Rajan, M. G. (1997). Global environmental politics: India and the North-South politics of global environmental issues: Oxford University Press.

Roberts, M., Stewart, B., \& Tingley, D. (2016). Navigating the Local Modes of Big Data: The Case of Topic Models. In R. Alvarez (Ed.), Computational Social Science: Discovery and 
Prediction (Analytical Methods for Social Research, pp. 51-97). Cambridge: Cambridge University Press. doi:10.1017/CBO9781316257340.004

Sardesai, R. (2014). 2014: The election that changed india. Gurgaon: Viking Pr.

The Hindu (2014, February 18). Escoms fail to meet solar power purchase target. The Hindu, p. unknown.

Weingart, P., Engels, A., \& Pansegrau, P. (2016). Risks of communication: Discourses on climate change in science, politics, and the mass media. Public Understanding of Science, 9(3), 261-283. https://doi.org/10.1088/0963-6625/9/3/304

Wessler, H., Wozniak, A., Hofer, L., \& Lück, J. (2016). Global Multimodal News Frames on Climate Change: A Comparison of Five Democracies around the World. The International Journal of Press/Politics, 21(4), 423-445. https://doi.org/10.1177/1940161216661848 